
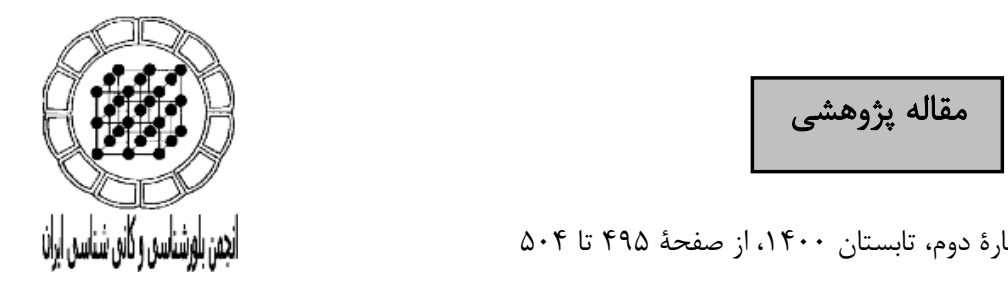

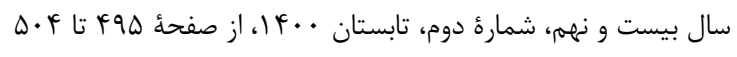

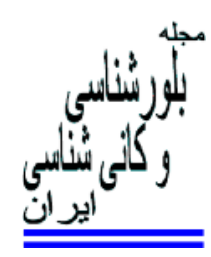

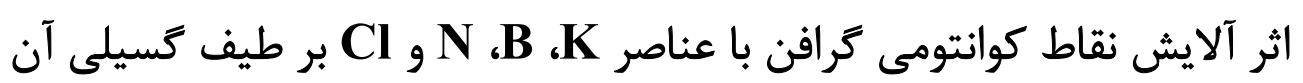

امين كاظمى او'، محمدرضا فدوى اسلام** ، غلامرضا يزدى

\author{
I - دانشكده فيزيك، دانشعاه دامغان، دامنان، /يران

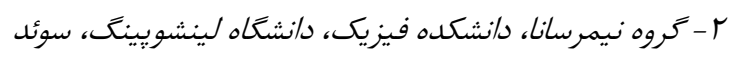

(دريافت مقاله: 99///T9، نسخه نهايى: 99/N/TF)

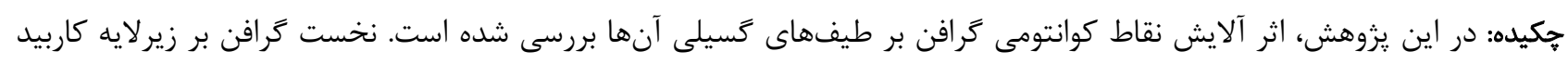

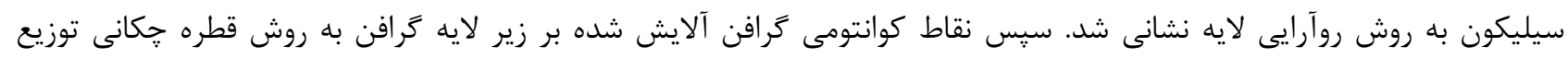

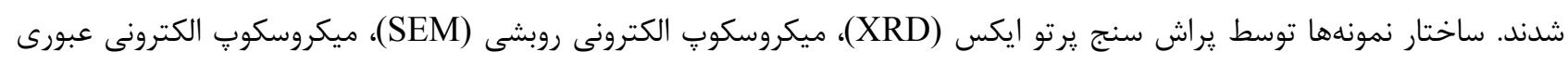

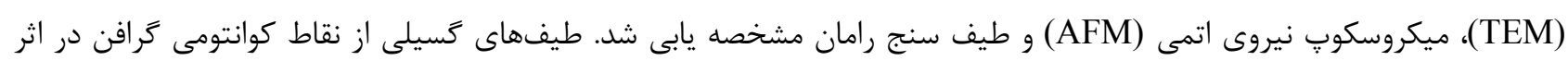

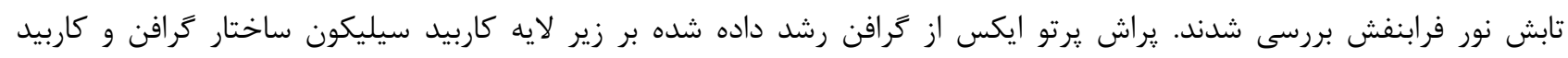

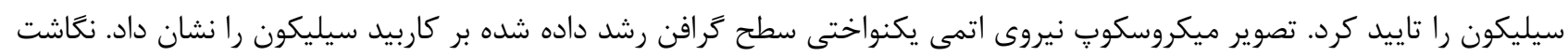

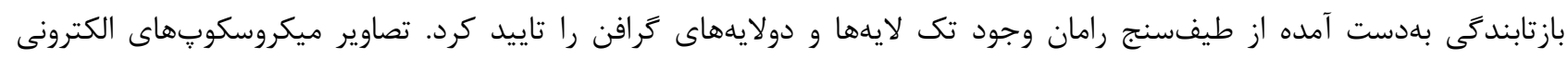

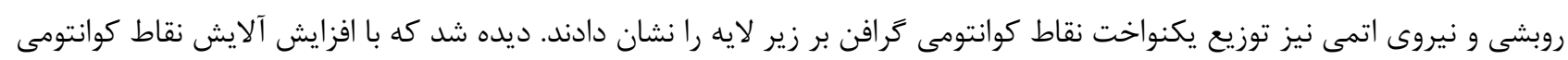

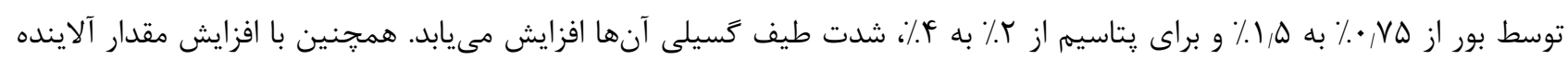

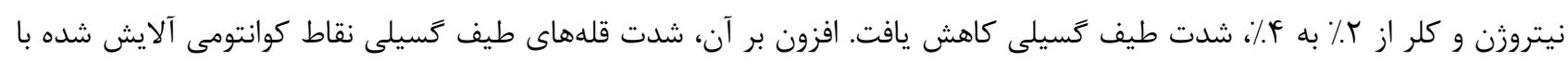

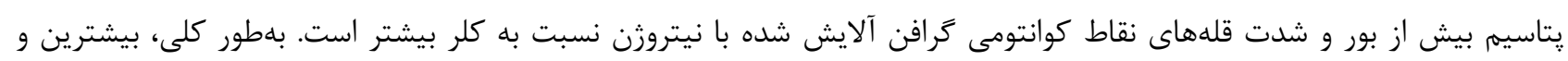

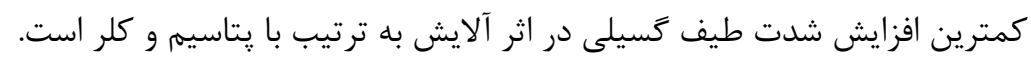

وازههاى كليدى: كرافن؛ نقاط كوانتومى كرافن؛ طيف كسيلى.

شود تا به صورت حسكرى زيستى بكار گرفته شود [. [1]. افزون

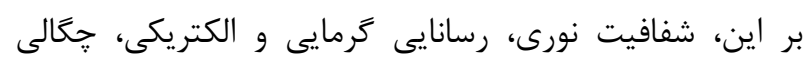

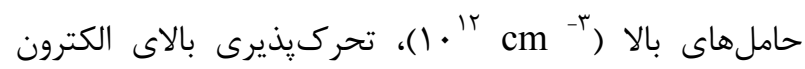

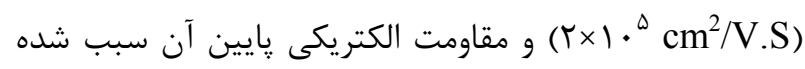

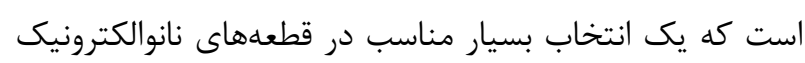

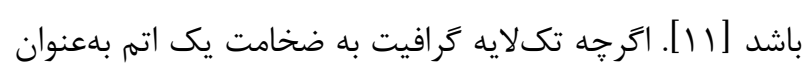

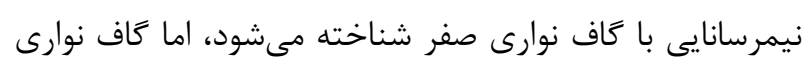

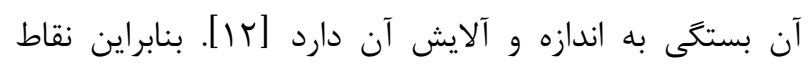

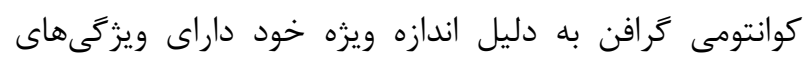

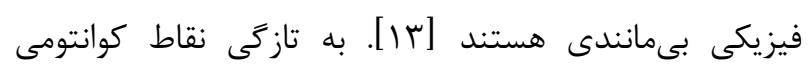

مقدمه نيمرساناها بدليل دارا بودن ويزگگ إنىاى متنوع و بىمانند

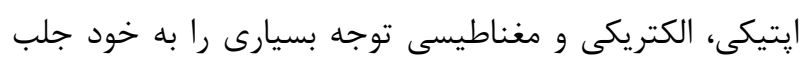

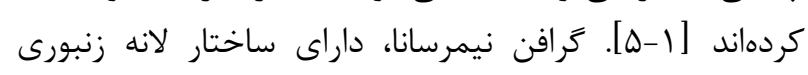

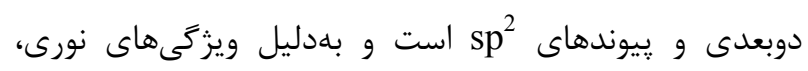

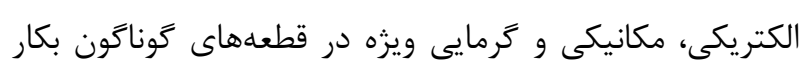

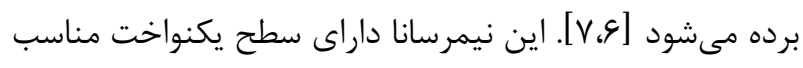
براى استفاده بهعنوان يك سطح حسكر است [1،، 9]. ترافن

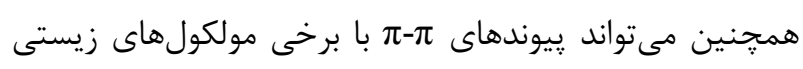

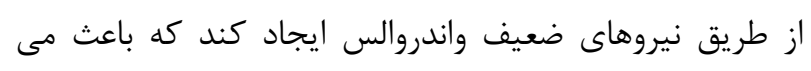


كاربردهايى جون حسكَى كَازى، تصوير بردارى زيستى، آشكارسازهاى نورى، تبديل انرزى، ديودهاى نور گسيل (LED) و سلولهاى خورشيدى آماده مى كند. روش آزمايش سنتز ترافن بر زيرلايه كاربيد سيليكون

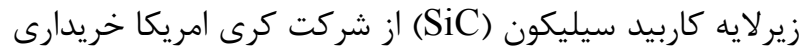

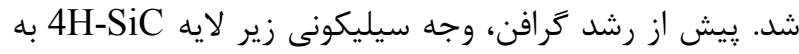

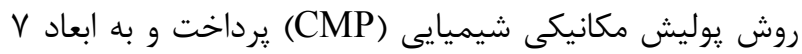

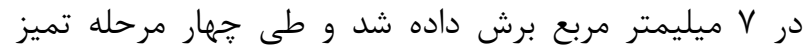

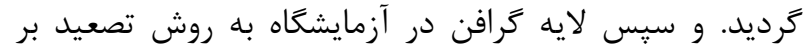

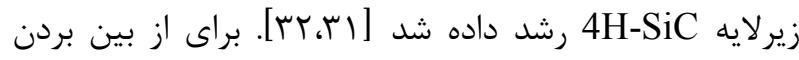
آلاينده هاى شيميايى روى سطح زير لايههاى كاربيد سيليكون

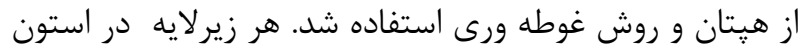

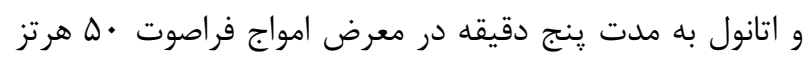

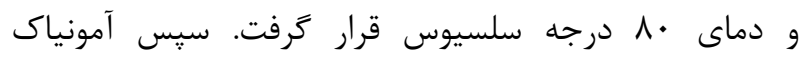
و آب اكسيرنه $\left(\mathrm{NH}_{3}\right)$

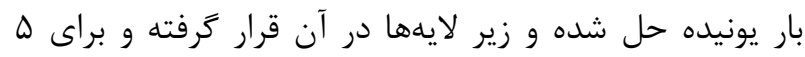

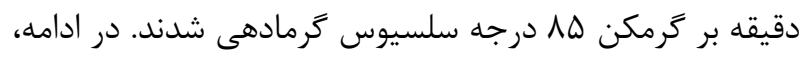

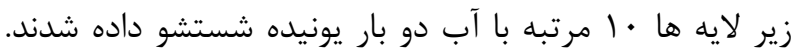

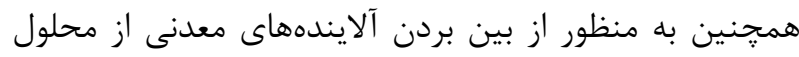

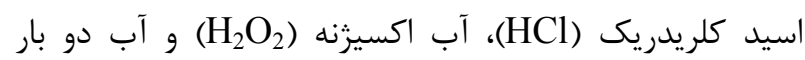

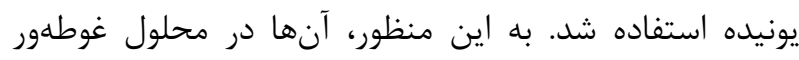

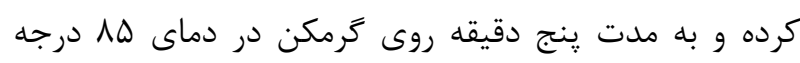

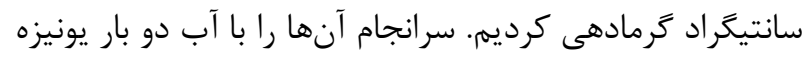

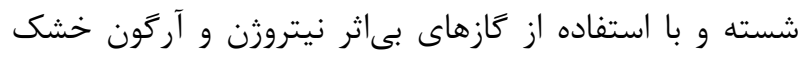

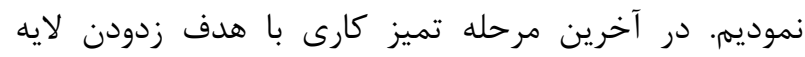

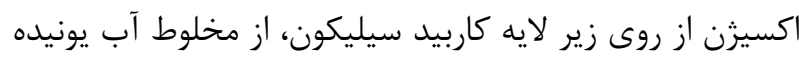

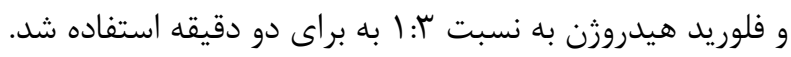

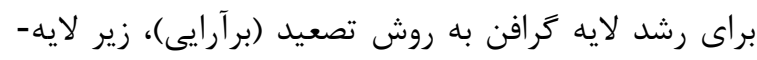

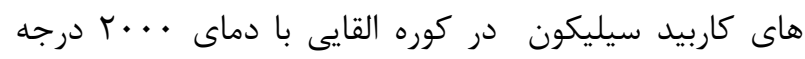

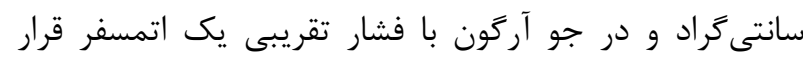

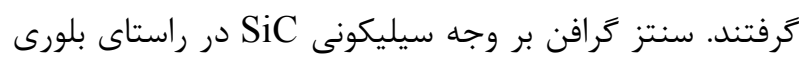
(1)

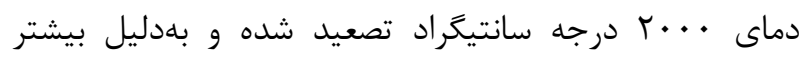

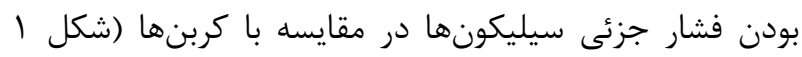

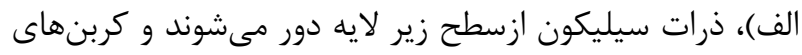

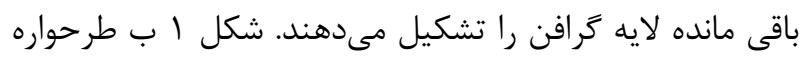

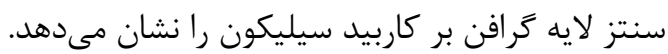

كرافن صفربعدى، بلهدليل محدوديتهاى كوانتومى و آثار لبهاى

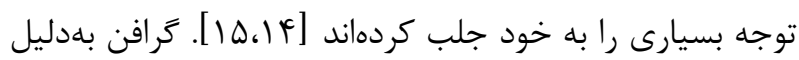
داشتن طيف نورى گسيلى مناسب در قطعه هاى إيتيكى نيز

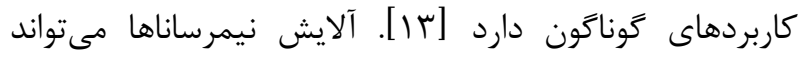

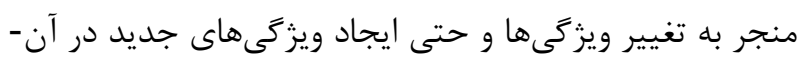
ها كردد [9 اع-19 19].

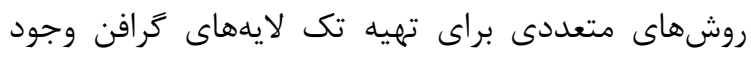

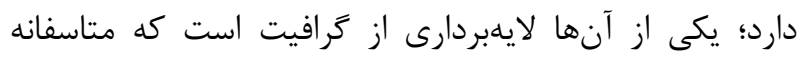

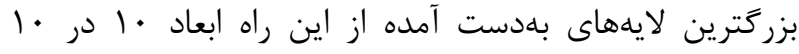

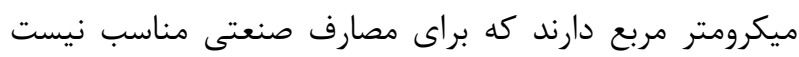

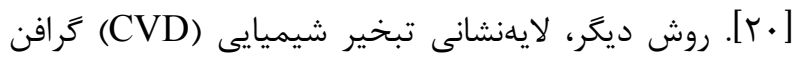

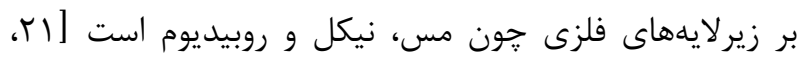

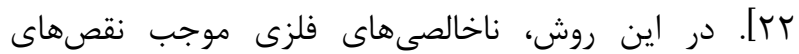

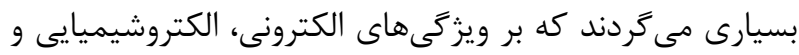

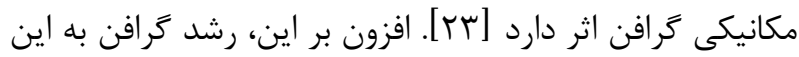

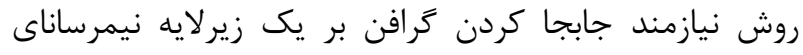

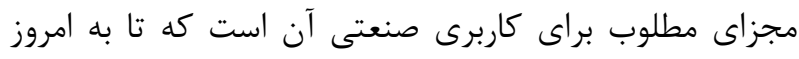

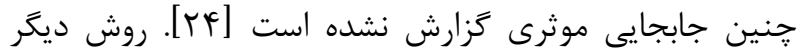

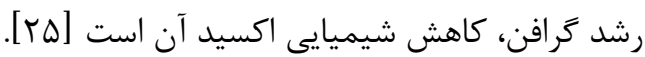

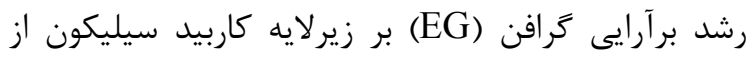

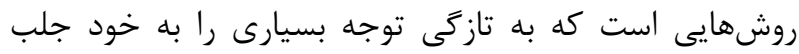

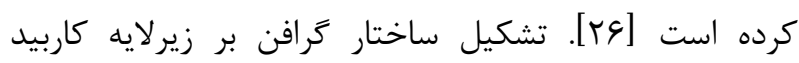

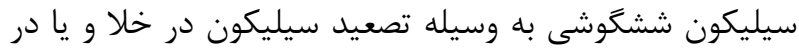

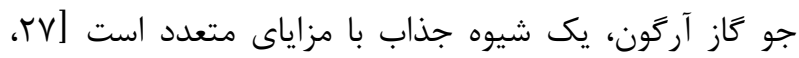

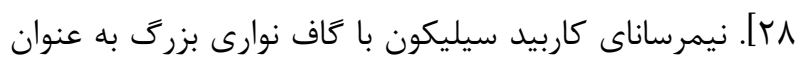

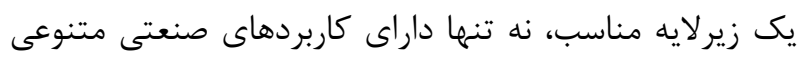

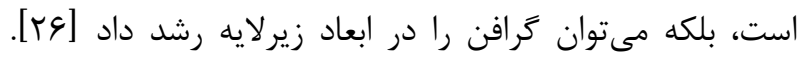

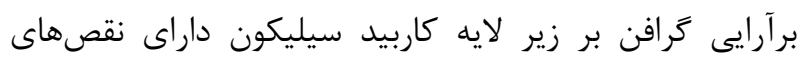

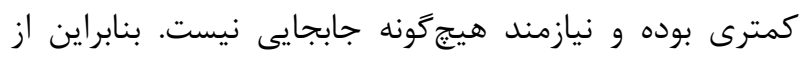

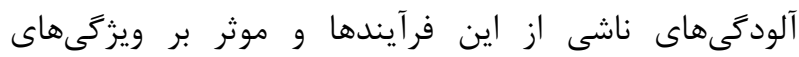

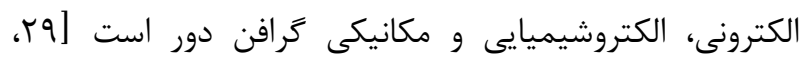

در اين يزوهش، گرافن به روش برآرايى بر زيرلايه كاربيد

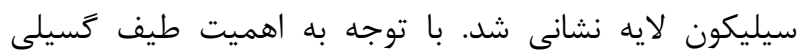

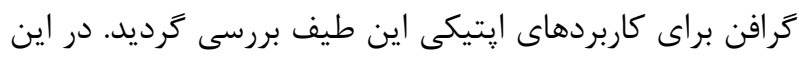

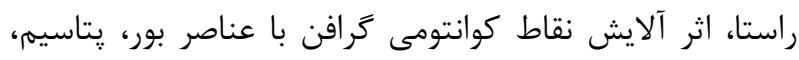

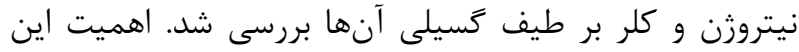

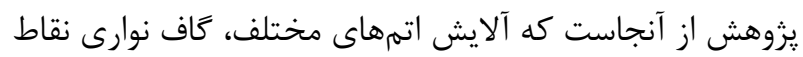

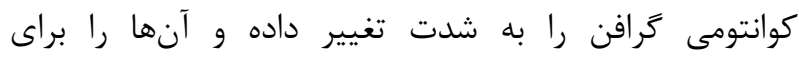




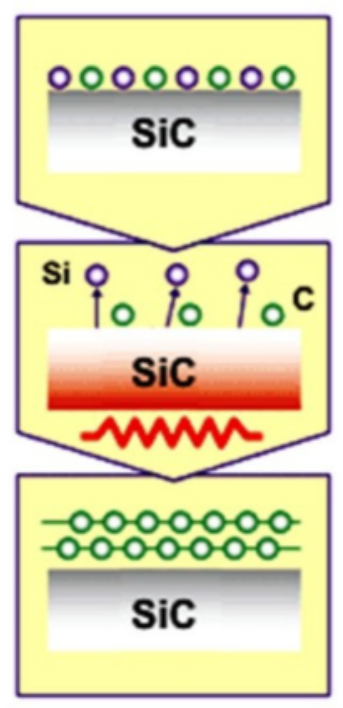

(ب)

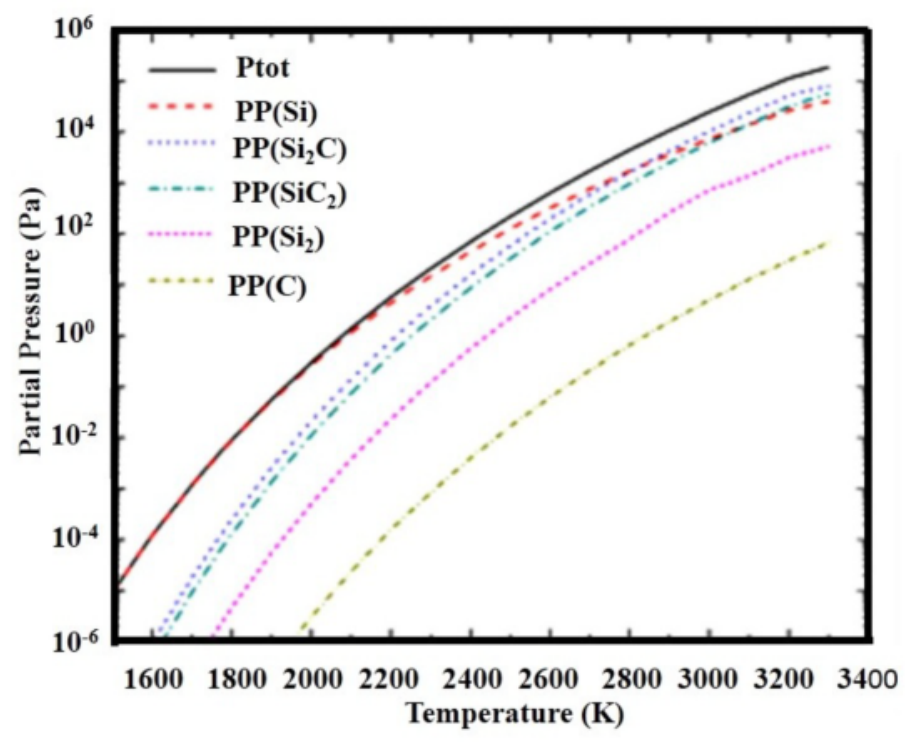

(الف)

شكل ا (الف) وابستكى دمايى فشار جزئى بخار مواد مختلف در تعادل با يك بلور روى زير لايه SiC [سب]، (ب) طرحواره سنتز لايه كرافن بر

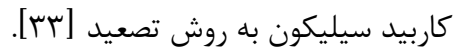

براى هيدروكسيد آمونيوم (NH4)

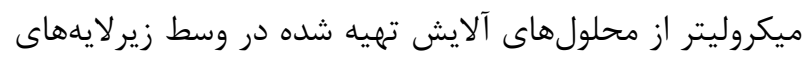
كرافن به روش قطره جكانى و توسط نمونه گير لايه نشانى شدند. سر انجام نمونهها در اتاق تميز و در محفظه هود و در دماى آزمايشعاه نكَه داشته شدند تا كامل خشك شوند.

\section{مشخصهيابى نمونهها} براى تعيين ساختار بلورى نمونهها از دستخاه يراش يرتو ايكس نمس مدل D8 ADVANCE-BRUKER (XRD) ريختار آنها توسط ميكروسكوٍ نيروى اتمى Digital

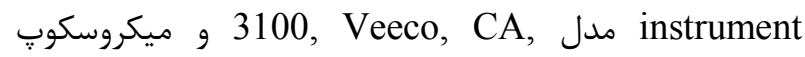
الكترونى روبشى زايس مدل LEO 1550 Gemini, تعيين

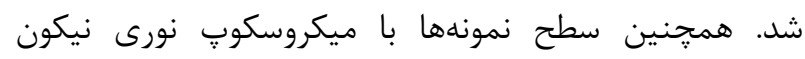
بر Infinity1 كرافن، نكاشت بازتابندگى سطح نمونه با طيف سنج ميكرو رامان kyoto مدل JobinYvon TRIAX 550, Kyoto

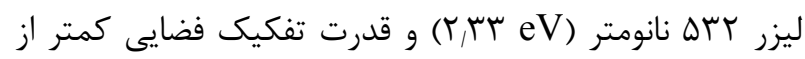

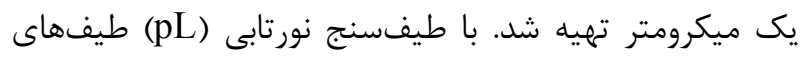
كَيلى از نقاط كوانتومى در اثر تابش نور فرا بنفش بررسى شد.
آلايش زير لايه كرافن با نقاط كوانتومى

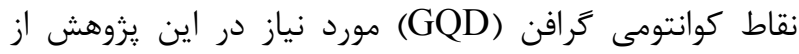

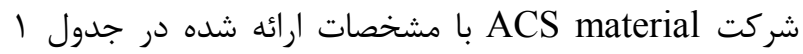
تهيه شدند.

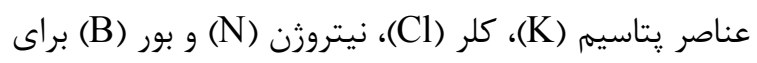

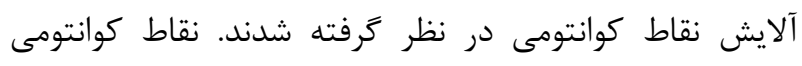

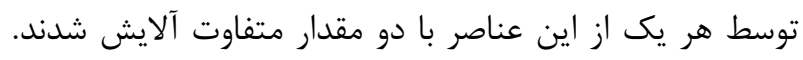
منبع عناصر آلايش در جدول r ارائه شده است. براى آلايش

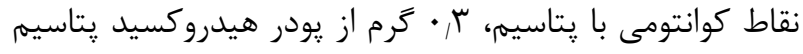

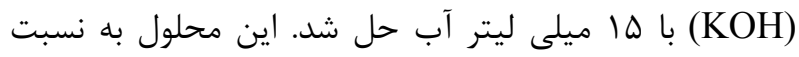

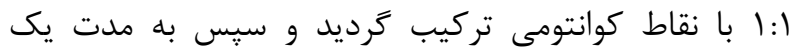

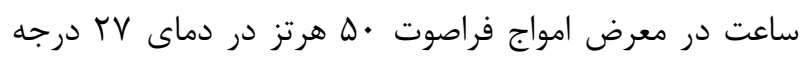

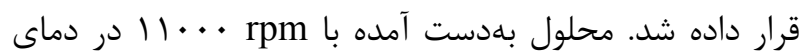

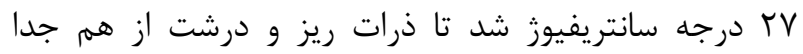

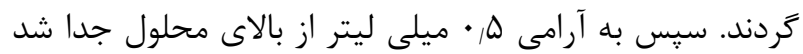

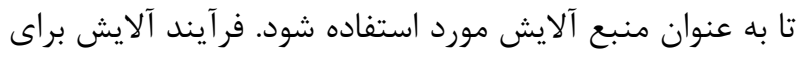
منبع يودرى اسيد بوريك $)$ (H.

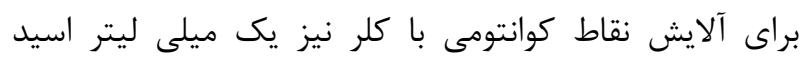

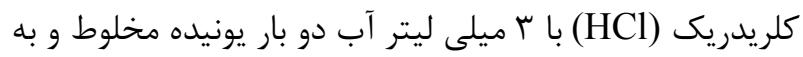
نسبت 1:ا با نقاط كوانتومى تركيب شد. اين فرآيند آلايش 


\begin{tabular}{|c|c|}
\hline \multicolumn{2}{|c|}{ جدول ا مشخصهاى نقاط كوانتومى گَرافن. } \\
\hline نقاط كوانتومى گَرافن & نام تركيب \\
\hline محلول بى رنغ & ظاهر \\
\hline 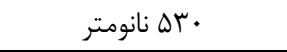 & قله نور تابى \\
\hline كمتر از 9 نانومتر & اندازه ذرات \\
\hline ا ميلى كرم بر ميلى ليتر & ج جالى \\
\hline آب (و مقدار كمى DMF ) & حلال \\
\hline
\end{tabular}

\begin{tabular}{|c|c|c|}
\hline & نقاط كوانتومى & جدول r الا \\
\hline غلظت آلايش & منبع آلايش & آلاينده (D) \\
\hline$\approx \cdot, v \Delta$ & \multirow{2}{*}{ (يودر) $\mathrm{H}_{3} \mathrm{BO}_{3}$} & \multirow{2}{*}{ بور (B) } \\
\hline$\approx 1, \Delta$ & & \\
\hline$\approx r$ & \multirow{2}{*}{$\mathrm{HCl}(37 \%)$} & \multirow{2}{*}{ كلر (Cl) } \\
\hline$\approx r$ & & \\
\hline$\approx r$ & \multirow{2}{*}{ (يودر) KOH } & \multirow{2}{*}{ يتاسيم (K) } \\
\hline$\approx \varphi$ & & \\
\hline$\approx r$ & \multirow{2}{*}{$\mathrm{NH}_{4} \mathrm{OH}(25 \%)$} & \multirow{2}{*}{ نيترورن (N) } \\
\hline$\approx \varphi$ & & \\
\hline
\end{tabular}

تصوير AFM نكاشت بازتابندگى ' از كرافن سنتز شده بر

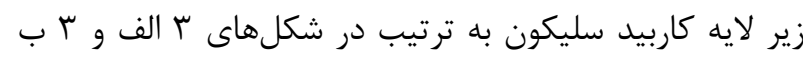

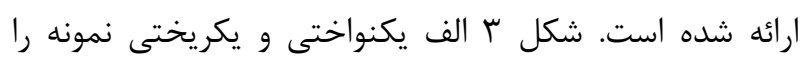

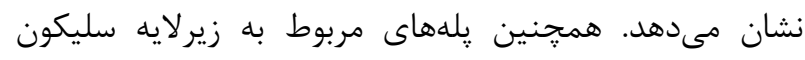

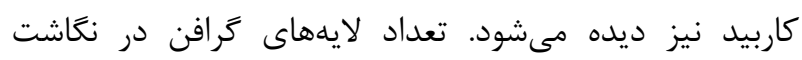

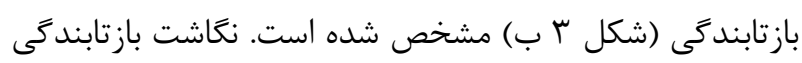

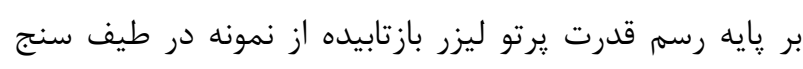

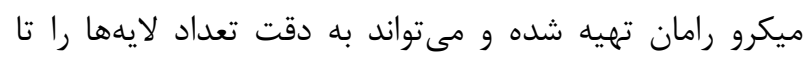

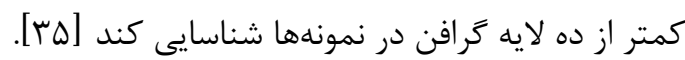

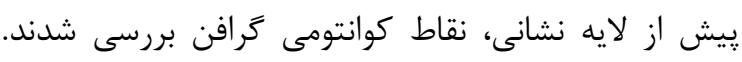

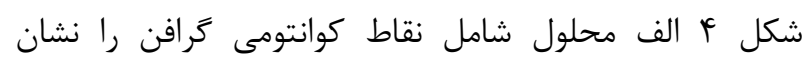

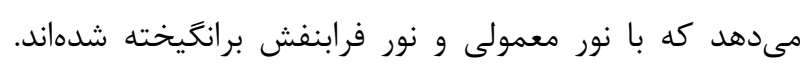

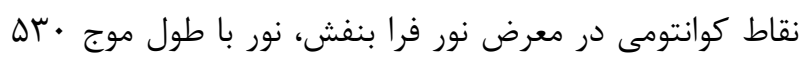

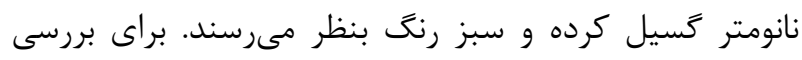

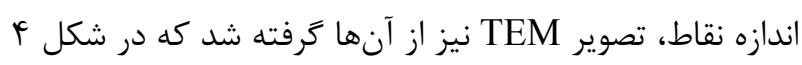

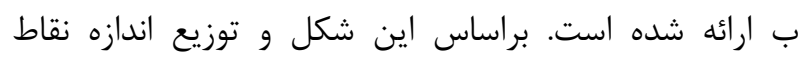

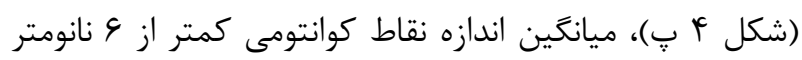

بحث و نتيجه گيرى براى بررسى ساختار كرافن سنتز شده برى زيرى زيرلايه كاربيد سيليكون، طيف سنجى XRD در زبتى زواياى خراشان' انجام شد.

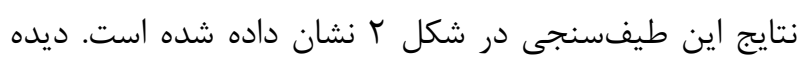

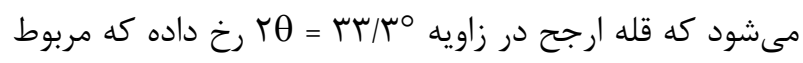

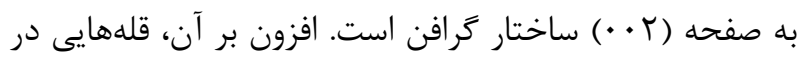
زواياى

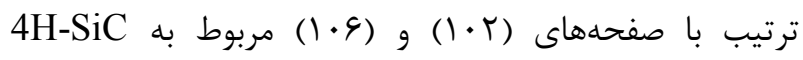

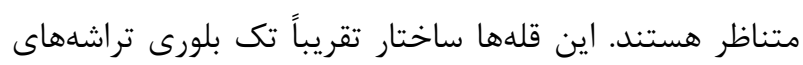

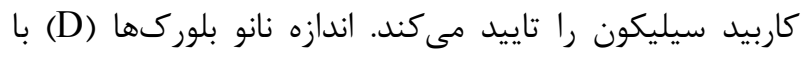
$D=\frac{0.94 \lambda}{\beta \cos \theta}$

محاسبه شد كه در آن، ג طول موج يرتو ايكس، $\beta$ يهنا در نيم

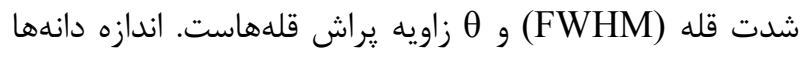

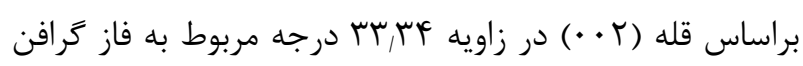

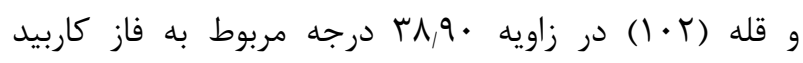

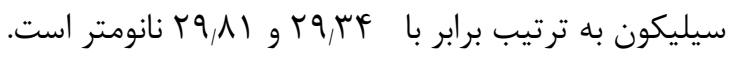




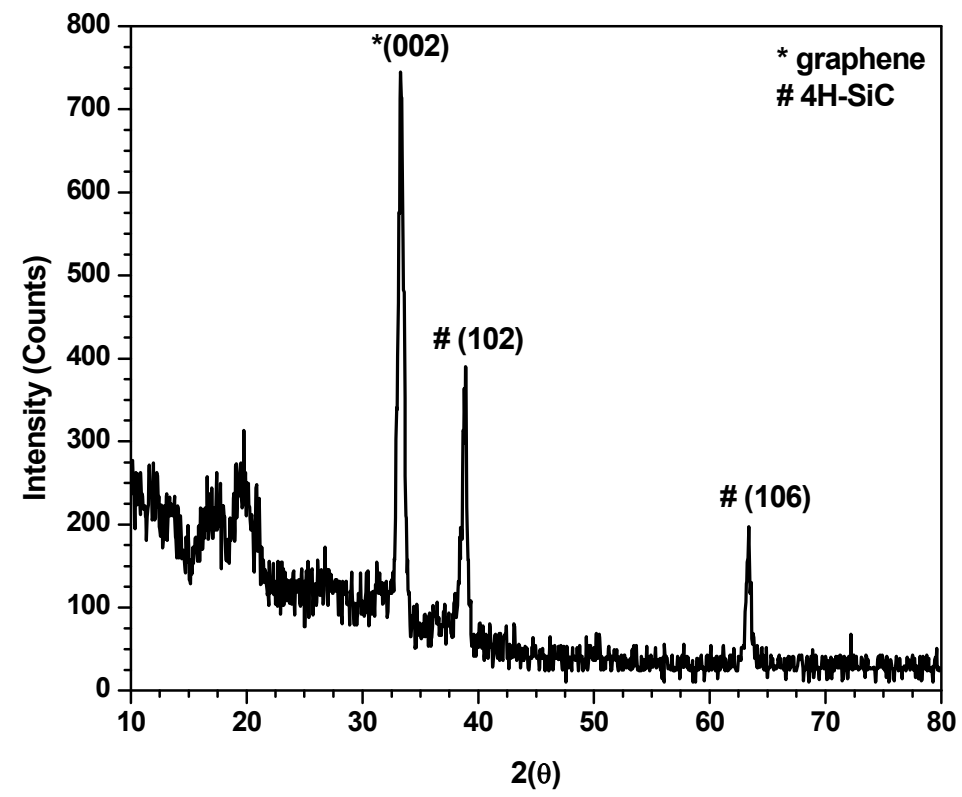

شكل r طيف XRD در زواياى خراشان از سطح گرافن رشد داده شده بر زيرلايه 4H-SiC
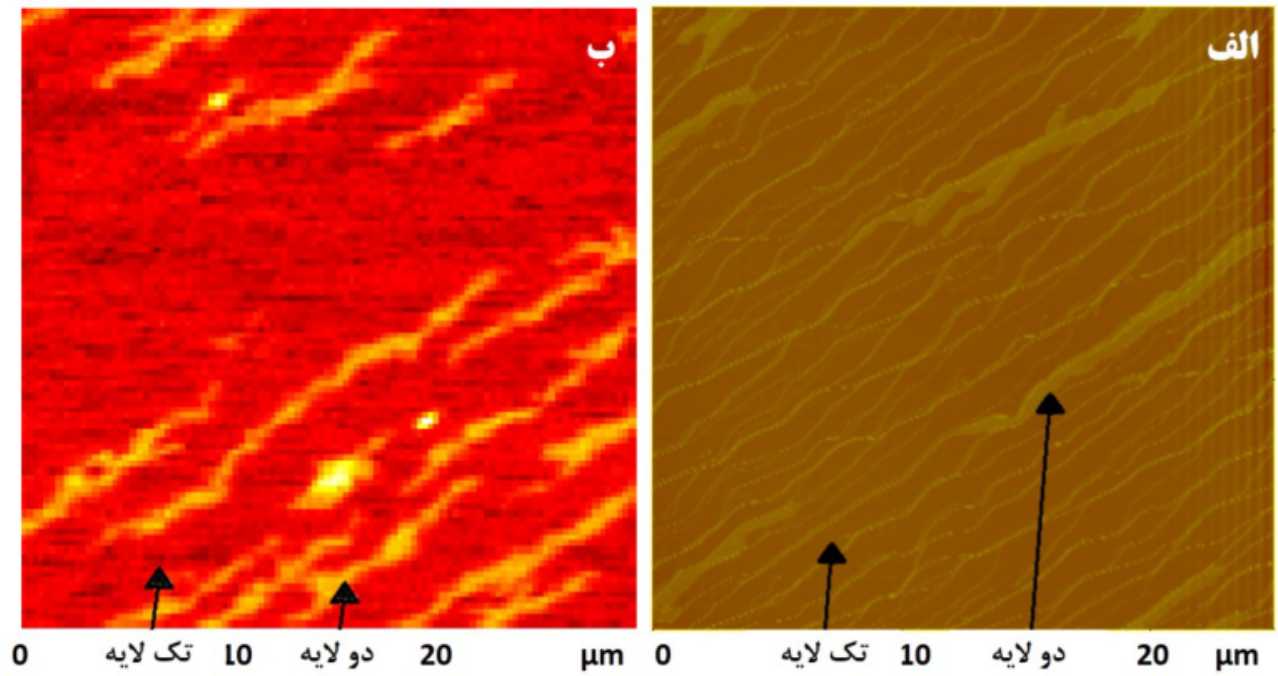

شكل ץ (الف) تصوير ميكروسكوٍ نيروى اتمى (AFM) از گرافن سنتز شده بر زيرلايه SiC و (ب) نكاشت بازتابندگى از نمونه در تصوير الف
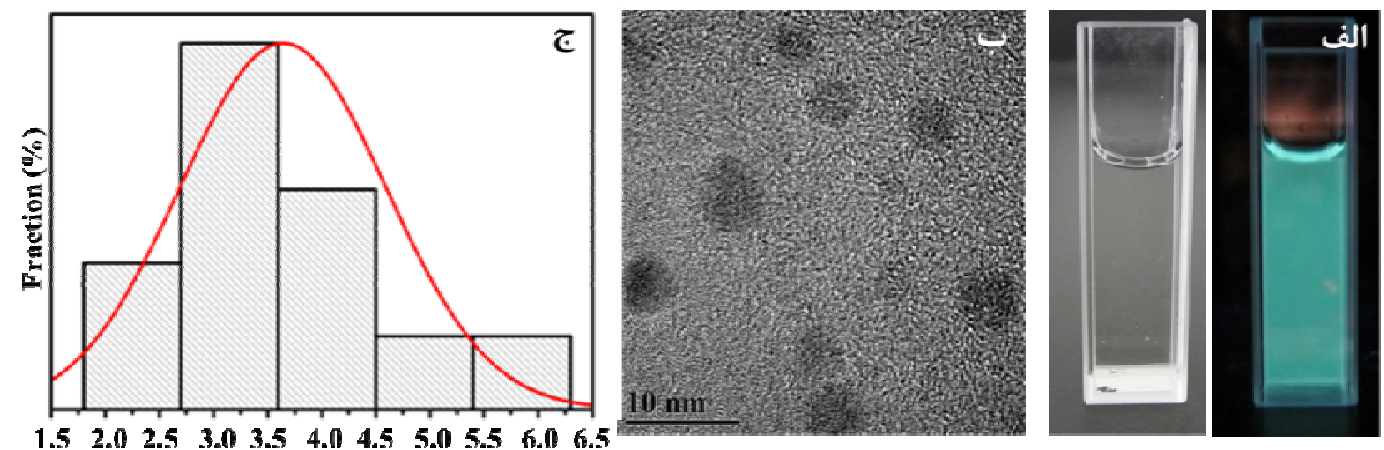

Size (nm)

شكل F (الف) تصوير نوركسيل نقاط كوانتومى گرافن در معرض نور معمولى كه شفاف ديده مىشوند (ج)) و نور UV كه به رنح سبز ديده

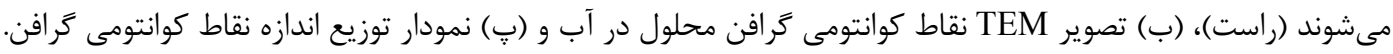


ريزتر براى لايهنشانى مناسبتر هستند، زيرا شامل مقدار

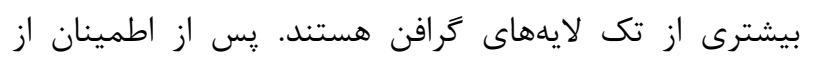

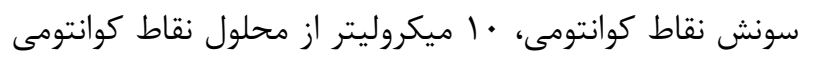

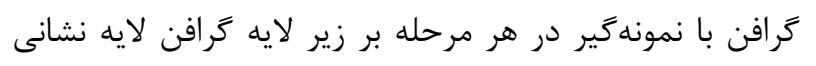

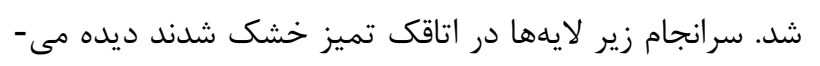

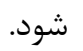

شكلهاى 9 الف و \& ب، به ترتيب نشان دهنده تصاوير AFM و SEM

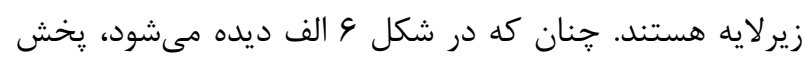
نقاط كوانتومى مطلوب است. همجنين با توجه به به شكل و

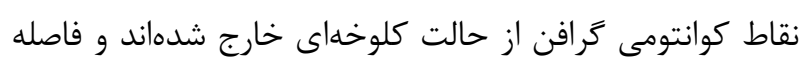
مناسبى از هم ديكر دارند.
يس از لايهنشانى نقاط كوانتومى بر زيرلايه، يك تصوير كلى

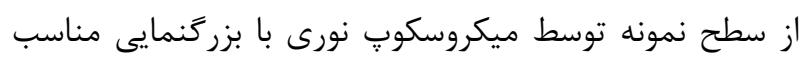

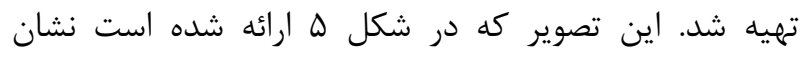

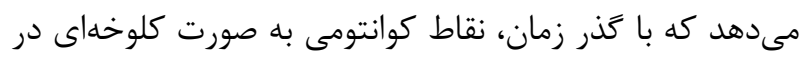

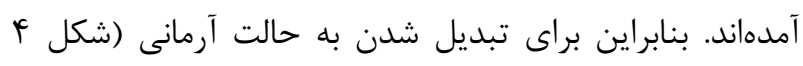

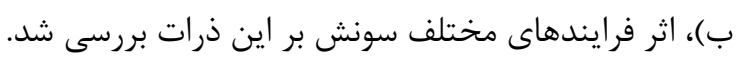

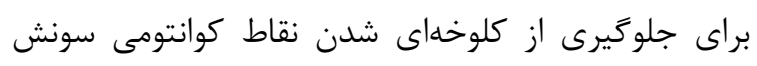

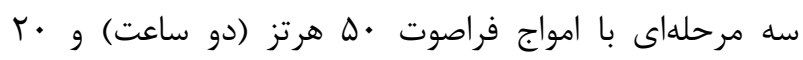
كيلوهرتز (نيم ساعت) دستغاه فرامركز گريزى و (سانتريفيوز)

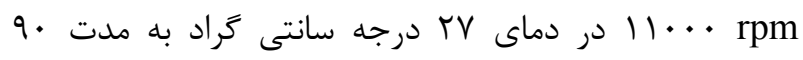

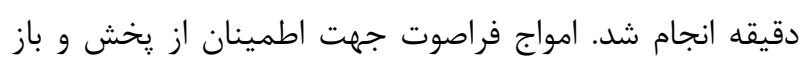

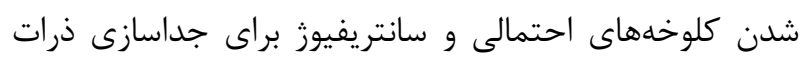

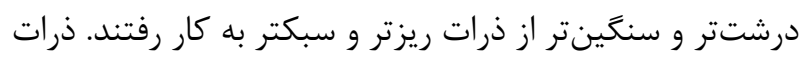

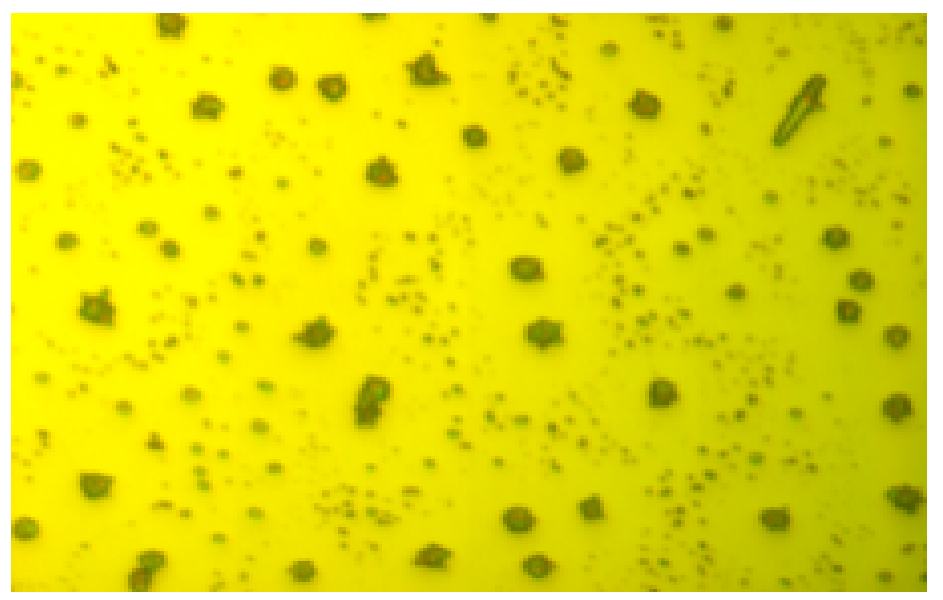

شكل ه تصوير ميكروسكوٍ نورى از نقاط كوانتومى كرافن كلوخه شده بر زيرلايه.
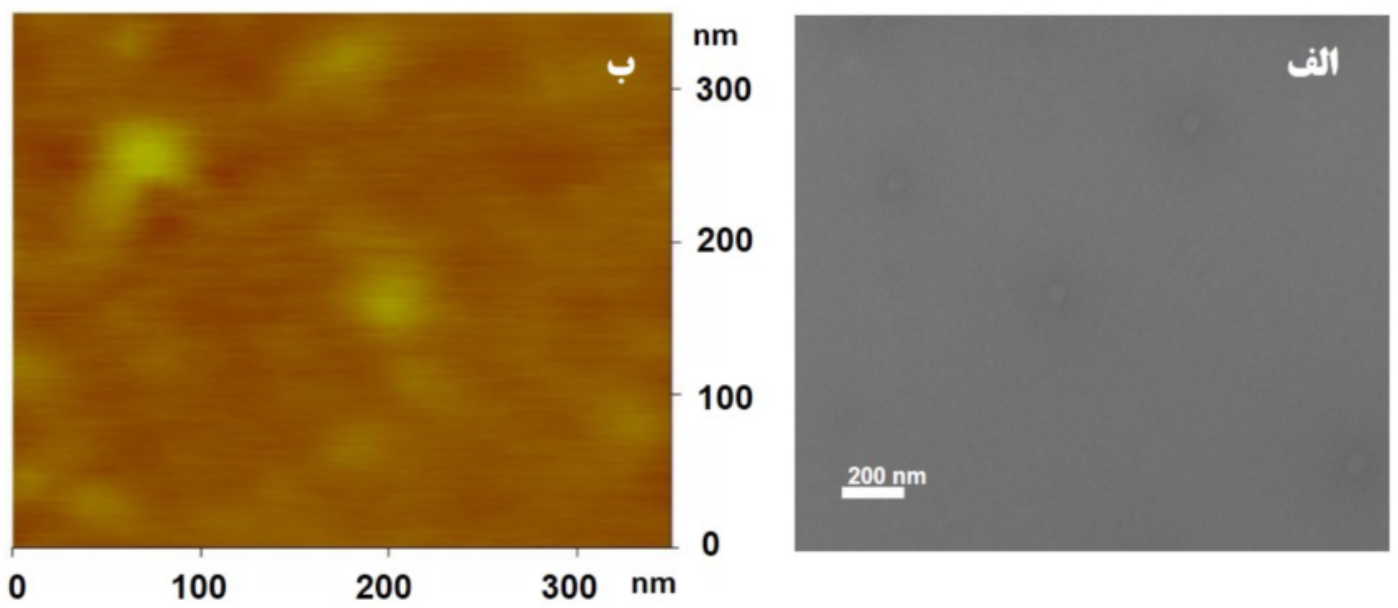

0

100

200

$300 \mathrm{~nm}$

شكل \& (الف) تصوير ميكروسكوب الكترونى روبشى (SEM) و ب) تصوير AFM از نقاط كوانتومى كَرافن نهشته شده بر زيرلايه كَرافن. 
كسيلى از نقاط كوانتومى آلايش شده افزايش مىيابد. مقايسه

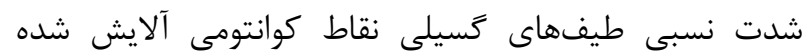
(شكل Vشان مى Vهد كه شدت قله مربوط به يتاسيم از همه

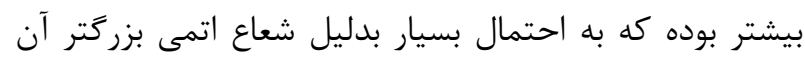
است. برداشت اثر آلايش نقاط كوانتومى گرافن نهشته شده بر زير لايه گرافن رشد داده شده بر كاربيد سيليكون بر طيفهاى گسيلى از آنها بررسى شد. تصاوير ميكروسكوٍ نيروى اتمى يكنواختى سطح

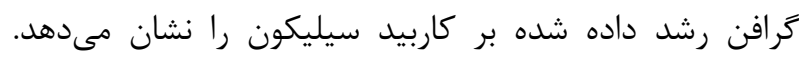

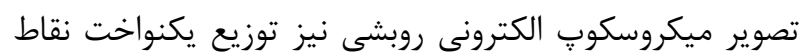
كوانتومى گرافن بر زير لايه را نشان مىدهد. با افزايش مئ ميزان

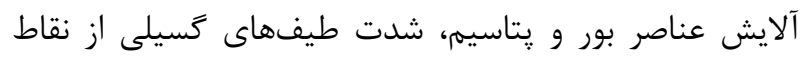

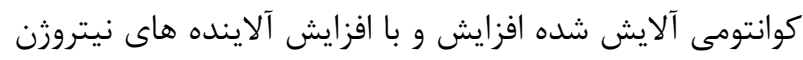
و كلر، شدت آنها كاهش مىيابد. با آلايش به مقدار يكسان از

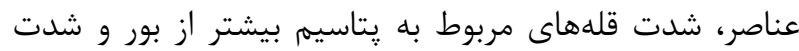

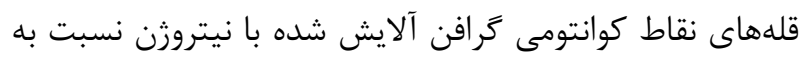

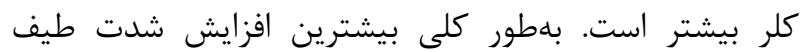

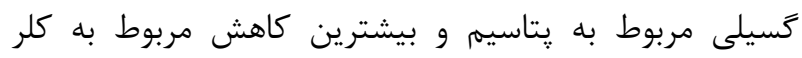

يديده نورتابى (pL) در نيمرساناها اهميت ويزهاى دارد. در اين يديده الكترونهاى نيمرسانا با جذب فوتونهاى نور برانگيخته

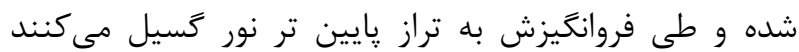

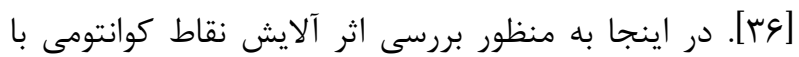

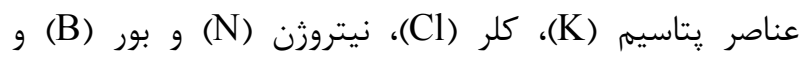
همجنين ميزان آلايش، براى لايههاى گرافن كه نقاط كوانتومى لهى آلايش و سونش شده بر آنها بهطور يكنواخت توزيع شدهاند لإنهائ

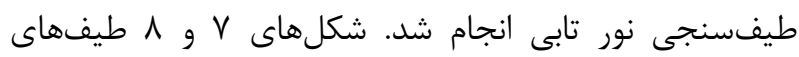
نورتابى نقاط كوانتومى گرافن آلايش شده با يتاسيهم، بور،

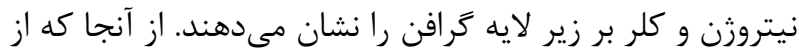

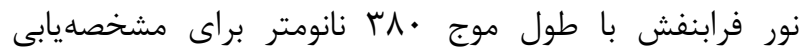

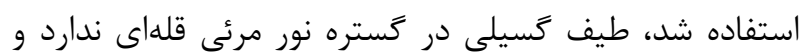

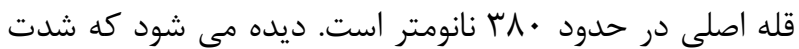

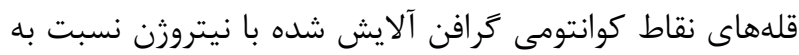

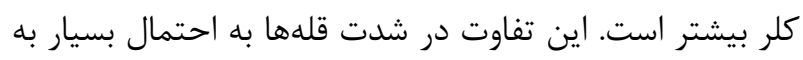
دليل بيشتر بودن الكترون خواهى نيتروزن (I, آT) و انرزى يونش

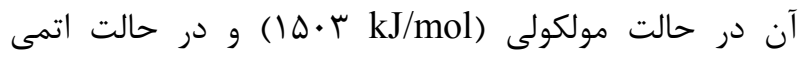

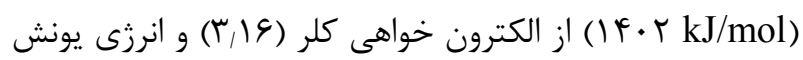
آن (kJ/mol

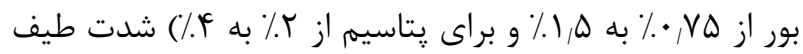

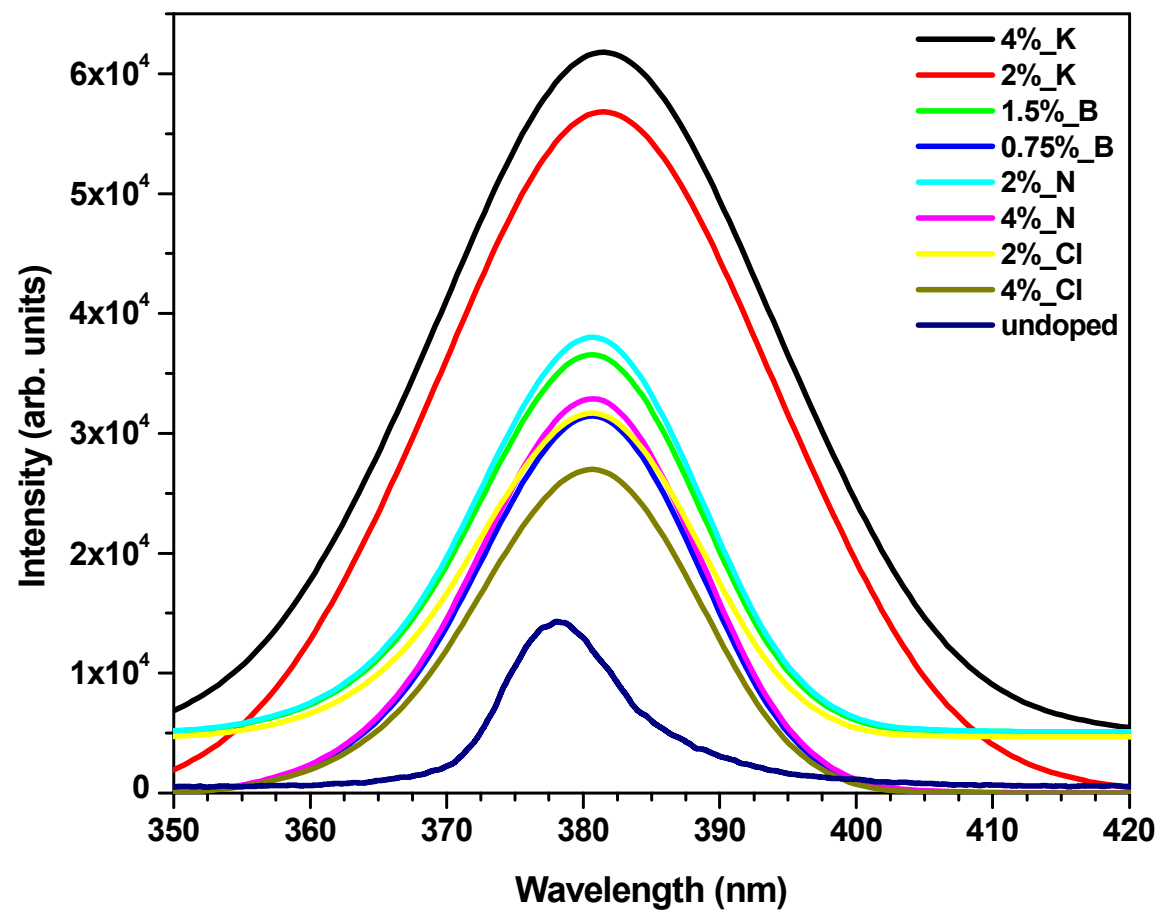

شكل V طيف نورتابى (PL) نقاط كوانتومى گرافن آلايش شده با پتاسيه، بور، نيترورن و كلر نهشته شده بر زيرلايه گرافن 

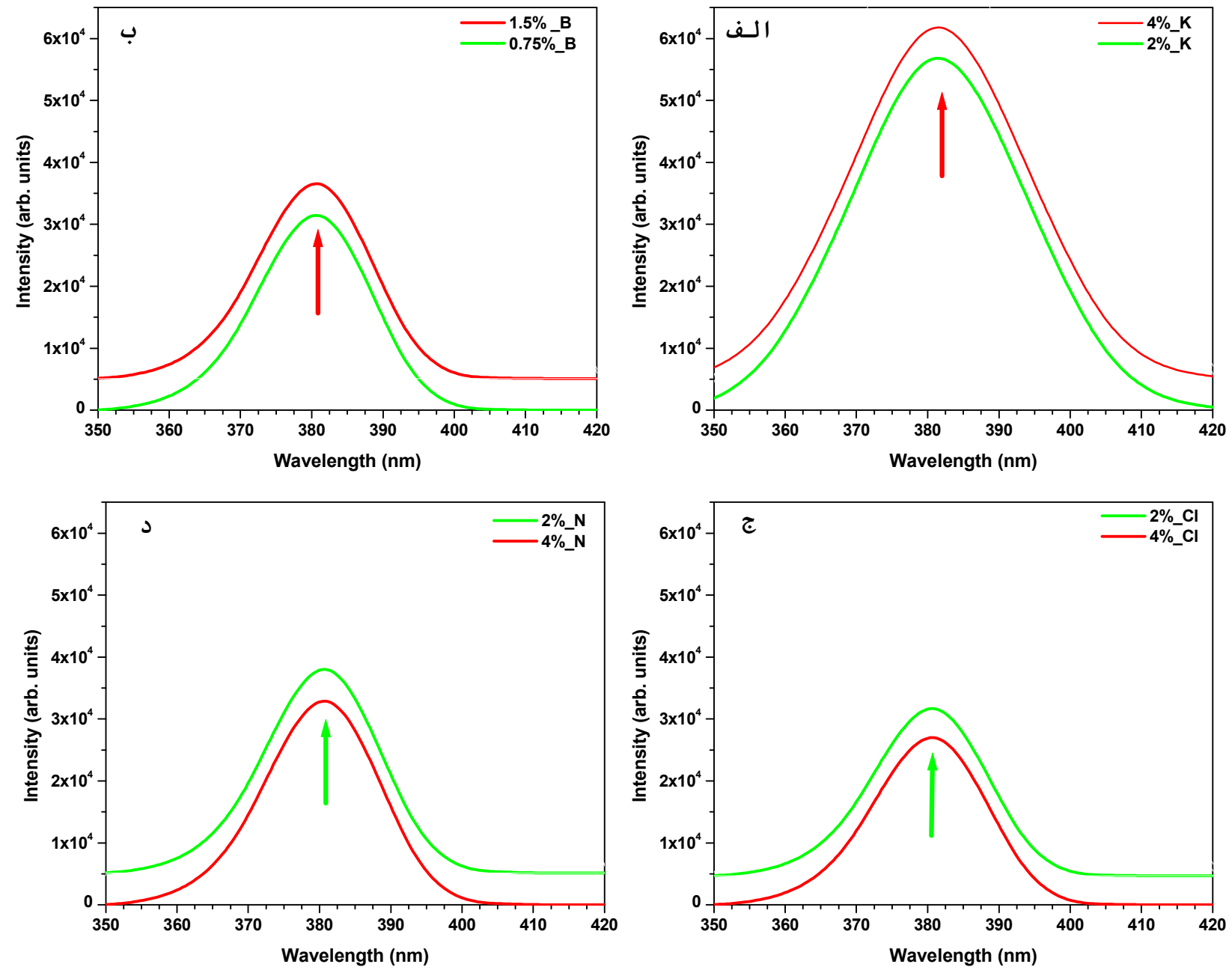

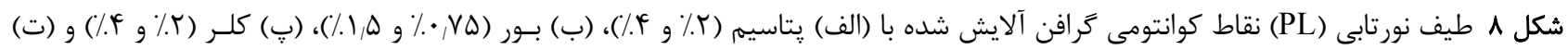

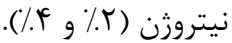

Crystallography and Mineralogy 24 (2016) 109116.

[4] Khosroabadi S., Kazemi A., "High efficiency gallium phosphide solar cells using TC-doped absorber layer", Physica E: Low-dimensional Systems and Nanostructures, 104 (2018) 116-123.

[5] Fadavieslam M.R., Kazemi A., "Influence of Ag concentration on the structure, optical and electrical properties of $\mathrm{SnS}_{2}: \mathrm{Ag}$ thin films prepared by spray pyrolysis deposition", Journal of Materials Science: Materials in Electronics, 28 (2017) 3970-3977.

[6] Geim, A.K., "Graphene: status and prospects", science 324.5934 (2009) 1530-1534.

[1] Zargar S., Poormoghadam A., Farbod M., "Fabrication and study of structural, optical and magnetic properties of $\mathrm{Zn}_{1-x} \mathrm{Ni}_{x} \mathrm{O}$ nanoparticles", Iranian Journal of Crystallography and Mineralogy 24 (2016) 309-316.

[2] Fadavieslam M.R., "Deposition and characterization of $\mathrm{SnO}_{2}: \mathrm{Sb}$ thin films fabricated by the spray pyrolysis method", Iranian Journal of Crystallography and Mineralogy 27 (2019) 739746.

[3] Niyaifar M., "Study of magnetic properties and Mössbauer spectroscopy of $Y_{3-x} \mathrm{Bi}_{x} \mathrm{Fe}_{5} \mathrm{O}_{12}$ prepared by sol-gel method", Iranian Journal of 
[17] Hasanpour A., Gharibshahi M., Niyarifar M., "Effect of cerium doping on the magnetic properties of yttrium iron garnet thin films on quartz substrates", Iranian Journal of Crystallography and Mineralogy, 23 (2015) 469478.

[18] Sarraf N., Hasanpour A., Hashemizade A., Akhound A., "Investigation of room temperature ferromagnetic behavior in $\mathrm{Mn}$ doped $\mathrm{ZnO}$ nanoparticles", Iranian Journal of Crystallography and Mineralogy, 23 (2015) 383-388.

[19] Salimian S., Farjami S., "The effect of temperature and annealing on the structural properties of CdS: Mn semiconductor nanocrystals", Iranian Journal of Crystallography and Mineralogy, 17 (2010) 621-628.

[20] Novoselov K.S., Geim A.K., Morozov S.V., Jiang D., Zhang Y., Dubonos S.V., Grigorieva I.V., Firsov A.A., "Electric field effect in atomically thin carbon films", science 306, 5696 (2004) 666-669.

[21] Li .X, Cai W., Colombo L., Ruoff R.S., "Evolution of graphene growth on $\mathrm{Ni}$ and $\mathrm{Cu}$ by carbon isotope labeling", Nano letters 9, 12 (2009) 4268-4272.

[22] Sutter P.W., Flege J.I., Sutter E.A., "Epitaxial graphene on ruthenium", Nature materials, 7 (2008) 406-411.

[23] Lee S.M., Kim J.H., Ahn J.H., "Graphene as a flexible electronic material: mechanical limitations by defect formation and efforts to overcome", Materials Today 18, 6 (2015) 336-344.

[24] Somani P.R., Somani S.P., Umeno M., "Planer nano-graphenes from camphor by CVD", Chemical Physics Letters, 430 (2006) 56-59.

[25] Robinson JT, Perkins FK, Snow ES, Wei Z, Sheehan PE. "Reduced graphene oxide molecular sensors", Nano letters 8, 10 (2008) 3137-3140.

[26] Berger C., Song Z., Li T., Li X., Ogbazghi A.Y., Feng R., Dai Z., Marchenkov A.N., Conrad E.H., First P.N., De Heer W.A., "Ultrathin epitaxial graphite: $2 D$ electron gas properties and a route toward graphene-based nanoelectronics", The Journal of Physical Chemistry B 108, 52 (2004) 19912-19916.

[27] Berger C., Song Z., Li X., Wu X., Brown N., Naud C., Mayou D., Li T., Hass J., Marchenkov
[7] Fredrik S., Geim A.K., Morozov S.V., Hill E.W., Blake P., Katsnelson M.I., Novoselov K.S., "Detection of individual gas molecules adsorbed on graphene", Nature materials 6, 9 (2007) 652655.

[8] Kaushik P.D., Rodner M., Lakshmi G.B.V.S., Ivanov I.G., Greczynski G., Palisaitis J., Eriksson J., Solanki P., Aziz A., Siddiqui A.M., Yakimova R., "Surface functionalization of epitaxial graphene using ion implantation for sensing and optical applications", Carbon, 157 (2020) 169-184..

[9] Kaushik P.D., Ivanov I.G., Lin P.C., Kaur G., Eriksson J., Lakshmi G.B.V.S., Avasthi D.K., Gupta V., Aziz A., Siddiqui A.M., Syväjärvi M., "Surface functionalization of epitaxial graphene on $\mathrm{SiC}$ by ion irradiation for gas sensing application", Applied Surface Science, 403 (2017) 707-716. [10] Ajayan, P.M., James M.T., "Nanotube composites", Nature 447, 7148 (2007) 1066-1068.

[11] Buehler, M.J., "Nanomaterials: Strength in numbers", Nature Nanotechnology 5, 3 (2010) 172. [12] Young-Woo S., Cohen M.L., Louie S.G., "Erratum: Energy Gaps in Graphene Nanoribbons", Physical Review Letters 98, 8 (2007) 089901.

[13] Raveendran N.R., Blake P, Grigorenko A.N., Novoselov K.S., Booth T.J., Stauber T., Peres N.M., Geim A.K., "Fine structure constant defines visual transparency of graphene", Science 320, 5881 (2008) 1308-1308.

[14] Çağlar Ö.G., Meyer J.C., Erni R., Rossell M.D., Kisielowski C., Yang L., Park C.H., Crommie M.F., Cohen M.L., Louie S.G., Zettl A., "Graphene at the edge: stability and dynamics", science 323, 5922 (2009) 1705-1708.

[15] Ritter K.A., Lyding J.W.,"The influence of edge structure on the electronic properties of graphene quantum dots and nanoribbons", Nature materials 8, 3 (2009) 235-242.

[16] Rabiee F., Ghazi M.A., Izadifar M, "Investigation of sensing properties of cobalt doped nickel-ferrite nanostructures synthesized by microwave method", Iranian Journal of Crystallography and Mineralogy, 23 (2016) 689698. 
a comparison with other SiC polytypes", Carbon 57 (2013) 477-484.

[32] Yazdi G.R., Iakimov T., Yakimova R., "Epitaxial graphene on $\mathrm{SiC}$ : a review of growth and characterization", Crystals 5 (2016) 53.

[33] Backes C., Abdelkader A.M., Alonso C., Andrieux-Ledier A., Arenal R., Azpeitia J., Balakrishnan N., Banszerus L., Barjon J., Bartali R., Bellani S., "Production and processing of graphene and related materials", 2D Materials 2 (2020) 022001.

[34] Monshi A., Foroughi M.R., Monshi M.R.,"Modified Scherrer equation to estimate more accurately nano-crystallite size using XRD", World journal of nano science and engineering 3 (2012) 154-160.

[35] Ivanov I.G., Hassan J.U., Iakimov T., Zakharov A.A., Yakimova R., Janzén E., "Layernumber determination in graphene on $\mathrm{SiC}$ by reflectance mapping", Carbon 77 (2014) 492-500.

[36] Wang Z., Zeng H., Sun L., "Graphene quantum dots: versatile photoluminescence for energy, biomedical, and environmental applications", Journal of Materials Chemistry C. (2015) 1157-65.
A.N., Conrad E.H., "Electronic confinement and coherence in patterned epitaxial graphene", Science 312, 5777 (2006) 1191-1196.

[28] Yakimova R., Virojanadara C., Gogova D., Syväjärvi M., Siche D., Larsson K., Johansson L.I., "Analysis of the formation conditions for large area epitaxial graphene on SiC substrates", Materials Science Forum, 645 (2010) 565-568.

[29] Suk J.W., Lee W.H., Lee J., Chou H., Piner R.D., Hao Y., Akinwande D., Ruoff R.S., "Enhancement of the electrical properties of graphene grown by chemical vapor deposition via controlling the effects of polymer residue", Nano letters 13, 4 (2013) 1462-1467.

[30] Pirkle A., Chan J., Venugopal A., Hinojos D., Magnuson C.W., McDonnell S., Colombo L., Vogel E.M., Ruoff R.S., Wallace R.M., "The effect of chemical residues on the physical and electrical properties of chemical vapor deposited graphene transferred to $\mathrm{SiO}_{2}{ }^{\prime \prime}$, Applied Physics Letters 99, 12 (2011) 122108.

[31] Yazdi G.R., Vasiliauskas R., Iakimov T., Zakharov A., Syväjärvi M., Yakimova R., "Growth of large area monolayer graphene on $3 \mathrm{C}-\mathrm{SiC}$ and 